\title{
DIEGO DE RIAÑO Y LA SACRISTÍA MAYOR DE LA CATEDRAL DE SEVILLA: NUEVAS CONSIDERACIONES SOBRE SU AUTORÍA
}

\section{DIEGO DE RIAÑO AND THE MAIN SACRISTY OF THE CATHEDRAL OF SEVILLE: A NEW APPROACH TO ITS AUTHORSHIP}

\author{
Juan Clemente Rodríguez Estévez \\ Universidad de Sevilla. España \\ ORCID: 0000-0002-0153-2207 \\ jcre@us.es \\ Antonio Luis Ampliato Briones \\ Universidad de Sevilla. España \\ ORCID: 0000-0001-8712-1099 \\ alab@us.es
}

Obra clave del Renacimiento español, la Sacristía Mayor de la catedral de Sevilla (1528-1547) ha sido objeto de una larga controversia, dejando tras de sí una sombra de duda sobre el nombre de su verdadero creador. En el seno de un trabajo más amplio que pretende depurar el catálogo de la obra arquitectónica de Diego de Riaño (c. 1490-1534), se plantea una revisión de este problema basada en el análisis conjunto de los documentos conservados y de la fábrica de cantería, ofreciendo nuevas evidencias que confirman la autoría del maestro cántabro y enriquecen la historia constructiva del monumento.

Palabras clave: Diego de Riaño; catedral de Sevilla; Sacristía Mayor; Renacimiento: siglo XVI.

Crucial Spanish Renaissance work, the Main Sacristy of the Cathedral of Seville (1528-1547) has been a long controversial issue, leaving behind it a shadow of doubt about the name of its true creator. In the context of a broader work, aiming to refine the building catalogue of Diego de Riaño (c. 14901534), a review of the problem has been posed. Based on the combined analysis of preserved historical documents and stonemasonry, new evidences confirm the authorship of the Cantabrian master and enrich the monument construction history.

Keywords: Diego de Riaño; Cathedral of Seville; Main Sacristy; Renaissance; $16^{\text {th }}$ century. 


\section{ESTADO DE LA CUESTIÓN}

La historiografía tradicional, desde Ceán Bermúdez ${ }^{1}$ hasta José Gestoso², había ligado el proyecto de la Sacristía Mayor de la catedral de Sevilla al maestro cántabro Diego de Riaño. Sobre el legado de Gestoso se construyó el relato constructivo del monumento, revisado con rigor a finales del pasado siglo por Teodoro Falcón ${ }^{3}$ y, sobre todo, por Alfredo Morales. A este último corresponde el estudio más completo sobre el edificio elaborado hasta el momento ${ }^{4}$, así como la recuperación de la trayectoria profesional de Riaño, documentada entre 1517 y $1534^{5}$.

A pesar de la importante base documental de estas aportaciones, una parte de la historiografía ha cuestionado la paternidad de Riaño para esta obra, acercándola en cambio a la figura de Diego de Siloe. Fue Manuel Gómez Moreno el principal defensor de esta posición al afirmar que Riaño poseía un estilo "goticista retardado en estructuras de derivaciones platerescas" y que "la Sacristía Mayor no pudo salir de su mente, y que si intervino Siloe decidiendo el rumbo de la obra y dirigiéndola hubo de ser sobre traza suya". Aunque matizaría sus afirmaciones en un trabajo posterior, centrando la aportación de Siloe en el diseño del abovedamiento $^{7}$, su hipótesis de partida caló en otros autores como Fernando Marías quien, en El largo siglo XVI, sugiere la autoría de Siloe basándose en criterios fundamentalmente estilísticos ${ }^{8}$.

* El presente trabajo se ha elaborado en el marco del Proyecto de Investigación I+D "Diego de Riaño, Diego de Siloe y la transición del Gótico al Renacimiento en España" (HAR 2016-76371-P).

${ }^{1}$ CEÁN BERMÚDEZ, Juan Agustín: Descripción artística de la Catedral de Sevilla. Sevilla, 1804 (ed. facsímil, Sevilla, 1981), pp. 114-124.

${ }^{2}$ GESTOSO Y PÉREZ, José: Sevilla monumental y artística. T. II. Sevilla, 1890 (ed. facsímil, Sevilla, 1984), pp. 398-405; y GESTOSO Y PÉREZ, José: Historia y descripción de la Sacristía Mayor de la Catedral de Sevilla y de las preciosidades artísticas que en ella se custodian. Sevilla, 1892, pp. 5-9.

${ }^{3}$ FALCÓN MÁRQUEZ, Teodoro: La catedral de Sevilla. Estudio arquitectónico. Sevilla, 1980, pp. 57-61.

${ }^{4}$ MORALES, Alfredo J.: La Sacristía Mayor de la Catedral de Sevilla. Sevilla, 1984, pp. 27-60.

5 MORALES, Alfredo J.: "Diego de Riaño en Lisboa", Archivo Español de Arte, 264, 1993, pp. 404-407; y MORALES, Alfredo J.: "Diego de Riaño", en El ciclo humanista. Arquitectos I (Proyecto Andalucía. Artistas andaluces y artífices del arte andaluz). T. XXV. Sevilla, 2011, pp. 191-225.

${ }^{6}$ GÓMEZ MORENO, Manuel: Las águilas del Renacimiento Español. Madrid, 1941, pp. $87-88$.

7 GÓMEZ MORENO, Manuel: Diego de Siloe. Granada, 1963, p. 39.

${ }^{8}$ MARÍAS, Fernando: El largo siglo XVI. Los usos artísticos del Renacimiento español. Madrid, 1989, pp. 403-404. 
Esta interpretación del problema halló su expresión más radical de la mano de Ricardo Sierra'. Su trabajo se basa casi exclusivamente en un exhaustivo análisis gráfico a través del cual se reafirma en la paternidad de Diego de Siloe. Sin aportar nuevos datos, en nuestra opinión el autor fuerza o elude los hechos documentados que pudieran comprometer su teoría, como la apertura de cimientos en 1532 o las grandes cantidades de piedra destinadas a la Sacristía Mayor entre 1532 y 1534 . Al tiempo, interpreta las cartelas existentes con fechas de 1534 y 1535: la primera aludiría a la colocación de la primera piedra y la segunda al comienzo de las obras de Siloe.

Entre los defensores de la autoría de Siloe, Aurora León había valorado el problema que suponía ignorar la documentación conservada ${ }^{10}$, proponiendo la existencia de un primer proyecto de Riaño, de planta rectangular, y de un segundo proyecto de Siloe que transformaría el organismo en el actual espacio centralizado. Sin embargo, la ausencia de cualquier discontinuidad en los paramentos actuales de la sacristía obliga a descartar la idea de un cambio importante de planteamientos en una obra ya iniciada.

Partiendo de estos antecedentes, trataremos de reconstruir el proceso constructivo del monumento a través de los documentos, en su mayoría conocidos pero también algunos nuevos, y de las hipótesis que elaboramos a partir del análisis perceptivo de la propia obra conservada.

\section{EL PROYECTO Y EL COMIENZO DE LA OBRA A PARTIR DE LOS DOCUMENTOS (1528-1532)}

En 1528, tras acceder al cargo de maestro mayor, Diego de Riaño presenta su propuesta general para las capillas de Alabastro, en los laterales del coro, así como para una ampliación del recinto catedralicio por su ángulo sureste, destinada a contener tanto las nuevas salas capitulares como la Sacristía Mayor (Figura 1) o la Sacristía de los Cálices (Figura 2) ${ }^{11}$. Independientemente de la posible integración de estructuras preexistentes y de la correspondencia o no de este primer proyecto con lo finalmente construido, la presentación de una estrategia de conjunto es un episodio lógico para alguien que acaba de asumir sus responsabilidades.

Sea por los cuantiosos recursos puestos en liza, sea por la incertidumbre sobre las diversas alternativas barajadas, las trazas se vieron sometidas a un largo proceso de ajuste y discusión. Finalmente, reunido el 22 de enero de 1530, el cabildo afrontó

9 SIERRA DELGADO, Ricardo: Diego de Siloé y la Nueva Fábrica de la Sacristía Mayor de la Catedral de Sevilla. Sevilla, 2012, pp. 93-142. Publicación de su tesis doctoral presentada en 1995.

${ }^{10}$ LEÓN ALONSO, Aurora: "La Sacristía Mayor de la Catedral de Sevilla, estilo e interpretación iconológica", Boletín de Arte, 4-5, 1984, p. 132.

${ }_{11}$ MORALES, Alfredo J.: La Sacristía Mayor..., op. cit., p. 27. 
la elección definitiva entre dos propuestas, la del maestro mayor y la de los maestros albañiles y carpinteros Sebastián y Diego Rodríguez, Francisco de Limpias y Sebastián Rodríguez de Escobar, lo que revela el manejo de una alternativa de cantería y otra de albañilería y madera. Tras estudiar las propuestas presentadas, los capitulares "[...] determinaron e mandaron que se faga la sacristia mayor e cabildo e sacristia de los calices juntamente [sic] según e como esta en la traza que fizo el dicho maestro mayor Diego de Riaño [...] e a si mesmo quel dicho maestro mayor Diego de Riaño tenga licencia e facultad e pueda alargar o cortar asi la dicha sacristia e cabildo e sacristia de los calices según e como a el le pareciere e bien visto fuese [... ${ }^{\prime \prime 12}$. De esta manera, podríamos decir solemne, quedaría Riaño al frente de una obra concebida con un planteamiento unitario -incluyendo las dos sacristías-, contando con un apoyo pleno del cabildo y con un amplio -y quizá insólito- margen de confianza para adaptar en lo sucesivo el proyecto hasta alcanzar su definitiva configuración.

Entre 1530 y 1532, se trabaja en las capillas de Alabastro, situadas en los costados del coro ${ }^{13}$. Iniciadas por Juan Gil de Hontañón en 1517, la obra quedó interrumpida en 1518, cuando se habían completado las dos situadas en el lado meridional. A la llegada de Riaño se retomó la construcción de las del lado norte. Los registros de entrada de alabastro en la obra abarcan exactamente los años 1530 y $1531^{14}$.

A comienzos de 1532, ya finalizando las mencionadas capillas, todos los esfuerzos se dirigieron hacia el nuevo cuadrante sureste, donde las iniciativas se aceleran. En enero de ese año se acuerda la traída de quinientas carretadas de piedra procedente de las canteras de Morón de la Frontera, hasta donde se desplazó Diego de Riaño con el objeto de organizar la saca de un material que se encarga explícitamente "para empeçar a fazer las sacristías"15. Nos parece oportuno subrayar de nuevo el plural de la expresión y, por tanto, la idea de que la totalidad del conjunto se está planteando de manera unitaria, más allá del estado en que se encontrara la Sacristía de los Cálices a la llegada de Riaño, un asunto sobre el que luego volveremos. Casi al tiempo, se ofrece a Diego de Riaño un sustancioso contrato, con una remuneración prevista de 70.000 maravedíes, que le obligará a trabajar durante ocho

12 Ibidem, p. 29.

13 GESTOSO Y PÉREZ, José: Sevilla monumental..., op. cit., pp. 271-278; FÁLCÓN MÁRQUEZ, Teodoro: La catedral..., op. cit., pp. 64-65; y MORALES, Alfredo J.: "La arquitectura de la catedral de Sevilla en los siglos XVI, XVII y XVIII", en La catedral de Sevilla. Sevilla, 1986, pp. 179-181.

${ }^{14}$ RODRÍGUEZ ESTÉVEZ, Juan Clemente: Los canteros de la catedral de Sevilla. Del gótico al Renacimiento. Sevilla, 1998, pp. 90-91.

${ }^{15}$ Según acuerdo de 5 de enero de 1532. MORALES, Alfredo J.: La Sacristía Mayor..., op. cit., p. 31. El 7 de febrero, se desplazaron a Morón Diego de Riaño, un canónigo y varios canteros de Utrera. La traída de las 500 carretadas se contrató el 18 abril y una parte debió ya llegar en verano, pues el 19 de septiembre se pagó el segundo tercio de la cantidad concertada, pago habitual a la mitad del trabajo. RODRÍGUEZ ESTÉVEZ, Juan Clemente: Los canteros de la Catedral..., op. cit., pp. 87-89. 
meses al año en la obra, compatibilizando esta tarea con su responsabilidad al frente de la colegiata de Valladolid ${ }^{16}$. Así, el cabildo se asegura la presencia del maestro, con un salario acorde a las extraordinarias condiciones de la empresa. Poco después, el 29 de julio, se le pide a Riaño que entregue las trazas de "las dos sacristías que agora tiene comenzadas", detallando especialmente la previsión de "rafas e dentellones" para trabar en algún momento posterior las obras del cabildo ${ }^{17}$. Este documento refleja el momento en que la construcción de las estancias capitulares se aplaza definitivamente para una segunda fase de los trabajos, que tardará bastantes años en llegar ya de la mano de otros arquitectos ${ }^{18}$. Para completar esta panorámica, en agosto de 1532 se paga a varios maestros de la ciudad "que visitaron las çanjas de la sacristia y dieron un pareçer" ${ }^{\prime \prime}$. El número y la diversidad de los citados permiten interpretar que se daba por concluida la apertura de las zanjas, una fase siempre comprometida para la que solía tomarse este tipo de precauciones ${ }^{20}$.

La mera exposición de toda esta información, una sucesión de noticias perfectamente coherentes con un proceso de esta naturaleza, sería en sí misma suficiente para certificar la responsabilidad de Riaño al frente de unas obras que estaban ya incuestionablemente en marcha desde principios de 1532, pero existen nuevos datos.

\section{LA OBRA DE LAS SACRISTÍAS HASTA LA MUERTE DE RIAÑO (1532-1534)}

El auto de 1530 transmitía claramente la decisión de construir un complejo unitario concebido como un conjunto de varias piezas: sacristías y cabildos. Incluso podría interpretarse que el texto anticipa la construcción simultánea de todo el conjunto, como de hecho ocurrió y pasamos inmediatamente a argumentar. Culminados los trabajos de cimentación en verano de 1532, se comenzarían a levantar diferentes lienzos murales cuya delimitación para el conjunto hemos reflejado en una planta (Figura 3), siguiendo una serie de consideraciones incluidas a lo largo

${ }^{16}$ MORALES, Alfredo J.: La Sacristía Mayor..., op. cit., p. 31.

17 Ibidem, pp. 31-32.

${ }^{18}$ El auto de 1530 mencionaba una sala capitular baja y otra alta. Sobre las estancias capitulares y el proyecto concebido por Riaño, vid. RECIO MIR, Álvaro: Sacrum Senatum: las estancias capitulares de la Catedral de Sevilla. Sevilla, 1999, pp. 96-98.

${ }^{19}$ Los trabajos de cimentación ya se habían previsto desde el año anterior, cuando se organizó la saca de piedra en Utrera y El Puerto con este objeto. Finalmente, todo se demoró hasta la fecha citada, utilizando exclusivamente la piedra portuense. MORALES, Alfredo J.: La Sacristía..., op. cit., pp. 31-32.

${ }^{20}$ Recuérdense, por ejemplo, los problemas que causarán en su momento los cimientos de la Capilla Real. FALCÓN MÁRQUEZ, Teodoro: La catedral..., op. cit., pp. 46-49; y MORALES, Alfredo J.: "La arquitectura de la catedral...”, op. cit., pp. 193-196. 
de este apartado. Con un cierto carácter de entidad autónoma, se dispuso un largo lienzo mural sobre los tres frentes de fachada posibles, articulado por un ritmo de monumentales pilastras clásicas absolutamente novedoso en el contexto urbano sevillano. Este lienzo rodeaba y otorgaba unidad a un conjunto de piezas en el que las nuevas formas renacentistas de la Sacristía Mayor estaban destinadas a convivir con la culminación en lenguaje tardogótico de la Sacristía de los Cálices (Figuras 1-2). Se ha discutido ampliamente sobre el estado de este último espacio, iniciado por Alonso Rodríguez en 1509, a la llegada de Riaño ${ }^{21}$. Nosotros estamos convencidos de que la aportación de Riaño a esta sacristía es muy elevada, alcanzando al conjunto de los cuatro pilares adosados, la totalidad de las bóvedas, y la ornamentación desplegada en torno al altar que la preside. Esta atribución, ya sugerida por los documentos de obra, puede apoyarse además en la identificación de la piedra utilizada, así como en su aparejado, como enseguida razonaremos.

Recientemente, se ha cuestionado la autoría de Riaño con respecto a esta obra, aduciéndose que el evidente parecido de su bóveda principal con la que preside la capilla mayor de la iglesia de Santa María de la Oliva, en Lebrija, nos lleva necesariamente a un escenario anterior a su maestría en la catedral. Sin embargo, la datación que se hace de esta última en 1520 resulta errónea, pues se ha confundido el objeto del que hablan los documentos manejados, que describen la actuación sobre una capilla mayor hoy desaparecida, inmediata a las antiguas naves alfonsíes. La actual y monumental cabecera fue levantada desde cimientos en fecha posterior, a partir de 1538, sobre los solares de unas casas vecinas, por Martín de Gaínza, sucesor de Riaño ${ }^{22}$.

Más allá del contenido literal del auto de 1530, la presencia en los muros de numerosas marcas de cantero nos ofrece sólidos indicios para pensar que todo el conjunto se fue levantando en alberca, con la excepción de los dos cabildos previstos, aplazados como ya vimos en 1532 y que no hemos recogido en nuestra planta. Las marcas, visibles en los interiores de las dos sacristías, en el caracol situado entre

${ }^{21}$ La compleja historia constructiva de la Sacristía de los Cálices ha suscitado un debate aún abierto, cuyo análisis desborda los límites de este trabajo. Para un acercamiento al asunto, vid. GESTOSO Y PÉREZ, José: Sevilla monumental..., op. cit., pp. 489-490; FALCÓN MÁRQUEZ, Teodoro: La catedral de Sevilla..., op. cit., pp. 61-62; MORALES, Alfredo J.: "La arquitectura de la catedral...", op. cit., pp. 181-193; RODRÍGUEZ ESTÉVEZ, Juan Clemente: "El maestro Alonso Rodríguez", en Los últimos arquitectos del Gótico. Madrid, 2010, pp. 287-289; y PINTO PUERTO, Francisco: "La Sacristía de los Cálices. Aportaciones desde el análisis de sus fábricas y los sistemas de control formal”, en La catedral entre 1434 y 1517: historia y conservación. Sevilla, 2013, pp. 165-233.

${ }^{22}$ Sobre la hipotética datación de la bóveda de Lebrija en 1520, véase ROMERO BEJARANO, Manuel y ROMERO MEDINA, Raúl: "La catedral de Sevilla y su conexión con la arquitectura del tardogótico portugués", en La Catedral entre 1434 y 1517: historia y conservación. Sevilla, 2013, pp. 259-263. Sobre la iniciación efectiva de la gran cabecera actual por Martín de Gaínza en 1538, véase BELLIDO AHUMADA, José: La patria de Nebrija (noticia histórica). $3^{\text {a }}$ ed. aumentada. Sevilla, 1985, p. 191. 
ambas y a todo lo largo de las fachadas, conforman un amplio conjunto de signos que podemos asociar al taller dirigido por Diego de Riaño (Figura 3), del que ofrecemos solo una selección y siempre de las situadas a menos de cuatro metros de altura $^{23}$. Resulta particularmente relevante el hecho que estos signos aparezcan siempre grabados sobre piedra procedente de Morón de la Frontera, y que signos idénticos aparezcan indistintamente inscritos sobre los elementos renacentistas de la Sacristía Mayor y sobre los elementos góticos, como el caracol entre las sacristías o en uno de los pilares de la Sacristía de los Cálices, apoyando la hipótesis de la simultaneidad constructiva de todas estas. Por otra parte, aparecen marcas idénticas sobre elementos parecidos y situados en lugares distantes. Esto permite identificar, por ejemplo, el extremo de levante del muro exterior, con las mismas marcas que en el interior.

Aparte las marcas de los canteros, otros aspectos relacionados con la fábrica nos ofrecen datos interesantes sobre el desarrollo de los trabajos. Centrando siempre nuestra atención en lo ocurrido entre los inicios de 1532 y el invierno de 1534, podemos aseverar que la ejecución de la fábrica se concibió en esos años con una solución material inédita en la historia de la catedral, ya que junto a la piedra calcarenita procedente de la Sierra de San Cristóbal, casi exclusiva en toda la gran fábrica gótica, a partir de 1532 entra por primera vez, y en grandes cantidades, la piedra procedente de las canteras de Morón de la Frontera. La piedra de Morón, traída por vía terrestre, de notable mayor calidad y precio, estaba destinada a labrar todos los elementos del orden arquitectónico y escultórico: pilares, cornisas, ornamentación, etc. La piedra de San Cristóbal, traída por vía marítimo-fluvial, de menor calidad y más económica, quedará relegada a las partes inferiores de los muros saliendo de la cimentación, así como a los entrepaños murales ${ }^{24}$. La combinación de estos dos materiales pétreos halla un precedente en la fábrica de la fachada del palacio del Rey Don Pedro, en los Reales Alcázares ${ }^{25}$; pero se trata de un hecho extraordinario y puntual, nunca planteado en la catedral hasta 1532. Fue sin duda Diego de Riaño, que había trabajado en la iglesia de San Miguel de Morón ${ }^{26}$, quien optó por utilizar la nueva piedra tanto en el Ayuntamiento de Sevilla ${ }^{27}$ como

${ }^{23} \mathrm{Al}$ conjunto de marcas registradas en el interior de las dos sacristías y en el caracol que se halla entre ambas, se han sumado recientemente las obtenidas en la fachada. Agradecemos al cabildo metropolitano y a don Jaime Navarro, arquitecto conservador del monumento, la posibilidad de acceder a los andamios instalados para la restauración de la citada fachada durante el año 2017.

${ }^{24}$ RODRÍGUEZ ESTÉVEZ, Juan Clemente: Los canteros de la Catedral..., op.cit., pp. 230 y $359-364$.

${ }^{25}$ VÁZQUEZ-CALVO, C. et al.: "Limestone on the Don Pedro I facade in the Real Alcázar compound, Seville, Spain”, en Geological Society, 331, 2010, pp. 171-182.

${ }^{26}$ MORÓN DE CASTRO, María Fernanda: La iglesia de San Miguel. Cinco siglos en la historia de Morón de la Frontera, siglos XIV-XVIII. Sevilla, 1995, pp. 71-81.

${ }^{27}$ MORALES, Alfredo J.: La obra renacentista del Ayuntamiento de Sevilla. Sevilla, 1981, pp. 34-35. 
en las dos sacristías catedralicias, donde la encontramos de manera sistemática y con idéntico criterio combinatorio tanto en el muro exterior que las envolvía como en todos los interiores.

Esta combinación de piedra nos permite también concretar una hipótesis sobre la parte de la fábrica mural de la Sacristía de los Cálices que se puede considerar preexistente y la ejecutada a partir de 1532. La piedra de Morón se utiliza en los cuatro pilares góticos, que no pueden ser así anteriores a 1532, mientras que el resto de los muros recibe piedra de San Cristóbal. Pero al tiempo podemos observar cómo los dos pilares de poniente están embebidos en un muro preexistente, por las discontinuidades en las líneas del aparejo, mientras que los del muro compartido con la Sacristía Mayor están labrados en perfecta continuidad de líneas con los entrepaños lisos pese al cambio de piedra ${ }^{28}$. Es bastante probable que el muro destinado a ser compartido por las dos sacristías fuera desmontado y labrado de nuevo desde cimientos por razones de seguridad en la estabilidad del conjunto, mientras que el de poniente, trasdosado exteriormente por el nuevo muro renacentista, fuera conservado pero recibiendo el embebido puntual de los pilares adosados (Figura 3). En nuestra hipótesis mural hemos considerado igualmente preexistente los trasdosados de las capillas laterales de la catedral hacia los Cálices.

Sobre la identificación petrográfica de los dos tipos de piedra podemos decir que la calcarenita de El Puerto se halla plenamente caracterizada, mientras que el material moronense solo ha sido identificado parcialmente. Con el objeto de certificar su naturaleza y procedencia, hemos podido realizar un análisis petrográfico, gracias a la colaboración del geólogo de la Universidad de Huelva, Teodosio Donaire, y los resultados han sido concluyentes: se trata de la misma piedra caliza que, combinada con la portuense, se ha identificado en la fachada del palacio del Rey Don Pedro ${ }^{29}$.

Para concluir este apartado, podemos decir que el avance efectivo de las obras entre 1532 y 1534 se puede considerar apoyado por diversas evidencias documentales. En primer lugar, a comienzos de 1533, cuando cualquier rectificación sobre el acceso al conjunto podría ya resultar, si no irreversible, difícilmente amortizable, se abordó la decisión sobre dónde y cómo abrir la puerta que conectaría la Sacristía Mayor con la propia catedral ${ }^{30}$. Por otra parte, cuando los recursos disponibles comenzaban a flaquear, se toman medidas radicales, como ocurrió el 19 de julio de 1533, cuando el cabildo decide "que la obra de las sacristías no cese [...] y no aya otra obra en la dicha iglesia", o el 30 de junio del mismo año, cuando el aparejador

${ }^{28}$ Análisis de paramentos cedido generosamente por Fernando Díaz Moreno (tesis doctoral en elaboración, Universidad de Sevilla).

${ }^{29}$ Las muestras tomadas en la fachada, tanto en el basamento como en las pilastras, responden a una piedra caliza (biomicrita/Wackestone de globigerinas), constituida casi en un $40 \%$ por globigerinas (foraminíferas planctónicas) y cantidades accesorias de cuarzo de grano muy fino, todo incluido en el cemento micrítico. Agradecemos al Dr. Teodosio Donaire su valiosa aportación.

${ }^{30}$ MORALES, Alfredo J.: La Sacristía..., op. cit., p. 33-34. 
Martín de Gaínza se comprometió con su taller a trabajar temporalmente, sin cobrar, para no parar la obra ${ }^{31}$. Finalmente, Gabriel de Aranda, biógrafo del padre Contreras, afirma, en noticia recogida por Teodoro Falcón, que a finales del verano de 1534 "se hallaba acabada de todo punto la gran Sacristía Mayor"32. Esta afirmación, como indica Falcón, no puede ser aceptada en su literalidad; pero, dada la precisión de los numerosos datos aportados por Aranda, sí podría interpretarse como un testimonio más de la ejecución relativamente avanzada de las obras en estos años.

\section{VOLUMEN DE OBRA CONSTRUIDO BAJO LA DIRECCIÓN DE RIAÑO (1532-1534)}

Como conclusión de todas las argumentaciones hasta ahora expuestas, aportamos a continuación un cálculo inédito del volumen total de piedra puesto en obra en el periodo que tratamos. Nuestro objetivo es realizar una estimación de la altura media - un simple dato estadístico- que podrían haber llegado a alcanzar los muros del conjunto de las sacristías durante los casi tres años de obra que van desde el comienzo de los trabajos, en 1532, hasta la muerte de Riaño a finales de 1534. Esta estimación exige varios pasos. En primer lugar necesitamos calcular el volumen total de piedra que entra en la catedral de Sevilla en el periodo 1532-1534, tanto procedente de las canteras de Morón como de las del Cerro de San Cristóbal. En segundo lugar necesitamos estimar la superficie total en planta que ocuparían los muros sobre los que se trabajó durante esos mismos años suponiendo, como ya hemos defendido, una construcción en alberca. Finalmente, mediante una simple división entre las dos cantidades, obtendremos una teórica altura media para la masa mural construida a finales de 1534 .

Sobre la primera cuestión, estimamos que entre 1532 y 1534 entran en la catedral de Sevilla un total de 1.112 carretadas de piedra procedente de las canteras de Morón de la Frontera ${ }^{33}$ y un total de 1.957 carretadas de piedra procedentes de las canteras del Cerro de San Cristóbal ${ }^{34}$.

Para calcular el volumen total de piedra de Morón necesitamos estimar la carga útil de una carretada. Las carretadas de Morón, que simultáneamente

${ }^{31}$ Ibidem, pp. 34-35.

32 DE ARANDA, Gabriel: Vida del [...] venerable padre Fernando de Contreras. Sevi1la, 1692, p. 329; y FALCÓN MÁRQUEZ, Teodoro: La catedral..., op. cit., p. 59.

${ }_{33}$ Distribuidas entre el verano de 1532 y el de 1534 pues, por razones que no podemos ahora aclarar, la contabilidad de fábrica no recoge pago alguno relativo al segundo semestre de ese último año. RODRÍGUEZ ESTÉVEZ, Juan Clemente: Los canteros de la Catedral..., op. cit., pp. 85-89.

${ }^{34}$ Distribuidas de la siguiente manera: 630,5 carretadas de tablas (dos tablas por carretada) y 1.326,6 carretadas de sillares ( 3 sillares por carretada). ACS (Archivo de la catedral de Sevilla), Libros de mayordomía de fábrica, n. 56, 57 y 58. 
llegan al Ayuntamiento, pesan $60 \operatorname{arrobas}^{35}$. No teníamos esa información directa para la catedral, pero el reciente hallazgo de un documento confirma igualmente esa cifra ${ }^{36}$. A partir del peso de una carretada estimamos finalmente el volumen total de piedra de Morón para el periodo 1532-1534:

- 60 arrobas de piedra de Morón, a 11,5 kg/arroba, son 690 kg/carretada.

- La densidad de la piedra caliza puede situarse en unos $2.200 \mathrm{~kg} / \mathrm{m}^{3} .^{37}$

- Con esta densidad, una carretada de $690 \mathrm{~kg}$ supone un volumen de $0,314 \mathrm{~m}^{3}$.

- Con 0,314 $\mathrm{m}^{3} /$ carretada, 1.112 carretadas dan un total de $349 \mathrm{~m}^{3}$.

Por su parte la piedra del Cerro de San Cristóbal, una vez descargada en el puerto sevillano, tendría unas condiciones de transporte hasta la catedral mucho más favorables, con un desplazamiento muy corto y un escaso desnivel del terreno, por lo que cabe esperar la obtención de un peso algo mayor para cada carretada. Como mencionamos anteriormente, sabemos que una carretada de piedra de San Cristóbal estaba compuesta exactamente por tres sillares ${ }^{38}$. Para las dimensiones de estos sillares obtenemos un dato medio realizando una medición directa de los hoy visibles en las zonas inferiores del muro de fachada, considerando que los mayores serían los más aproximados a los sillares transportados, siendo el resto producto del corte de los anteriores. Así, la dimensión media de un sillar de El Puerto puede fijarse en: $34 \mathrm{~cm}$ x $42 \mathrm{~cm}$ x $92 \mathrm{~cm}$, lo que nos da un volumen de unos $0,131 \mathrm{~m}^{3}$ por sillar. Por tanto:

- Tres sillares de San Cristóbal, a 0,131 m³/sillar, suponen 0,393 m³/carretada.

${ }^{35}$ El 14 de abril de 1533, el cantero Juan López de Lorrieta se comprometía a sacar para la obra del Ayuntamiento 500 carretadas de piedra de Morón, siendo "cada carretada de sesenta arrovas e que sea la piedra de la vitola que Diego de Riaño, Maestro Mayor questá presente, me diere". RODRÍGUEZ ESTÉVEZ, Juan Clemente: Los canteros de la Catedral..., op. cit., p. 393.

${ }^{36}$ En un pago ejecutado el 29 de abril de 1533, se le entregó a un carretero de Utrera 2.312 mrs. (68 reales) "que los ovo de aver por seis carretadas de piedra de la de morón menos veynte arovas que el truxo de las canteras, a doze reales cada carretada... 2.312 mrs.". ACS, Fábrica, Libros de cargo y data, $\mathrm{n}^{\circ} 57,1533$, f. 8. Sabemos por tanto que una carretada de piedra vale 12 reales que, a $34 \mathrm{mrs} . /$ real, son $408 \mathrm{mrs}$. Si hubieran sido 6 carretas completas, el pago total habría ascendido por tanto a $2.448 \mathrm{mrs}$. La diferencia entre este pago teórico y el realizado $(2.312 \mathrm{mrs}$. ) es de $136 \mathrm{mrs}$., que sería el precio de las 20 arrobas de menos. Finalmente, 408 mrs. que vale una carretada es el triple de 136 mrs. que valen 20 arrobas, luego una carretada de piedra transporta 60 arrobas de peso.

${ }^{37}$ Frontera entre caliza "dura" y "muy dura" según la tabla 3.1.1 del apartado 3 del catálogo de elementos constructivos del CTE (Código Técnico de la Edificación, Ministerio de Fomento).

38 Aplicamos el mismo valor de volumen a la carretada de tres sillares como a la de dos tablas. 
- Con 0,393 $\mathrm{m}^{3} /$ carretada, 1.957 carretadas dan un total de $769 \mathrm{~m}^{3}$.

Sumando los dos tipos, podemos por tanto estimar un volumen total de piedra de $1.118 \mathrm{~m}^{3}$ que entraría en la catedral de Sevilla en vida de Riaño, entre 1532 y 1534. Estimado este volumen total, el siguiente paso consiste en estimar la superficie total en planta de los muros sobre los que se habría estado trabajado durante esos años, que es la que hemos resaltado sobre el plano del conjunto a partir de las diversas consideraciones expuestas a lo largo del apartado anterior (Figura 3).

La superficie en planta de la estructura mural sobre la que creemos se trabaja a finales de 1534 supone un total de $275 \mathrm{~m}^{2}$. Con un volumen total de piedra de 1.118 $\mathrm{m}^{3}$, obtenemos una altura media de la posible masa mural construida a finales de 1534 de 4,07 $\mathrm{m}$ de altura (Figura 4). Hemos plasmado en el dibujo una distribución homogénea del volumen construido, no con la intención de establecer una fotografía exacta de un momento constructivo, que en realidad mostraría un perfil mucho más variado, probablemente con un acento mayor en el centro, sino con el deseo de visualizar un valor medio que, en cualquier caso, estimamos sumamente significativo.

Aproximadamente $4,20 \mathrm{~m}$ es la altura a la que se sitúa la cartela con la fecha de 1534 que aparece en una de las columnas de la cabecera de la Sacristía Mayor, fecha que, relacionada directamente o no, coincide con la de la muerte de Riaño. Es también conocido cómo una segunda cartela con la fecha de 1535 aparece en el interior del presbiterio a una altura aproximada de $5,60 \mathrm{~m}$. Es evidente que, en torno a la muerte del maestro, existe una gran coherencia sobre el avance de las obras entre el cálculo que surge de su gestión económica y lo que sugieren las evidencias epigráficas, aparte de todo el resto de consideraciones hasta aquí expuestas.

Entre junio y octubre de 1534, se recogen pagos a diversos carpinteros por el montaje de una grúa en la obra para elevar los materiales ${ }^{39}$. La instalación de este medio auxiliar solo puede corroborar la idea de que los trabajos han avanzado hasta esa fecha significativamente.

\section{CONSIDERACIONES FINALES}

La objeción planteada -y posteriormente revisada- por Manuel Gómez-Moreno, con la que empezábamos estas páginas, sobre la dificultad de admitir la autoría de Diego de Riaño, maestro del gótico, para la obra renacentista de la Sacristía Mayor es una cuestión digna de consideración. Pero su auténtica trascendencia solo puede ser seriamente abordada evitando violentar la realidad de unos hechos que pueden ser minuciosamente descritos desde una abrumadora diversidad de perspectivas. Podemos afirmar, con la máxima rotundidad, que Diego de Riaño proyectó el conjunto de las dos sacristías catedralicias - una de nueva

${ }^{39}$ MORALES, Alfredo J.: La Sacristía..., op. cit., p. 36. 
planta y otra reformada- y su muro de cierre perimetral, proyecto que fue definitivamente aprobado en 1530. Podemos afirmar igualmente que Riaño dirigió la puesta en obra de todos estos elementos, concluyendo la cimentación en el verano de 1532 y elevando a continuación la totalidad de la estructura mural de manera simultánea. Las marcas de canteros conservadas en los sillares en diferentes lugares del recinto confirman que el conjunto de la obra evolucionó en alberca. La piedra de Morón de la Frontera, una novedad absoluta en la historia de la catedral, entra en grandes cantidades a partir de enero de 1532 y es perfectamente reconocible en todos los paramentos. El volumen de piedra documentado permite calcular que la obra alcanza una altura media en torno a los 4 metros a finales de 1534, a la muerte del maestro, altura que coincide con la de la cartela que contiene dicha fecha situada sobre una de las columnas. Podemos finalmente añadir que esta altura media, cuya distribución real supondría probablemente un desarrollo algo mayor en la parte central, implicaba una situación lo suficientemente consolidada como para poder afirmar que cualquier variación sobre el planteamiento inicial del proyecto solo podría ser ya viable a nivel de los abovedamientos y, aún así, teniendo en cuenta el reducido margen de opciones que implicaría para éstos la muy singular y específica configuración de la planta y sus órdenes.

Toda la información acumulada apoya abrumadoramente la excepcional circunstancia de que el maestro cántabro trabajaba con un mismo taller en dos espacios diferentes, uno tardogótico y otro renacentista ${ }^{40}$. Dicha circunstancia, tal como defendiera en su momento Alfredo Morales $^{41}$, confirma la versatilidad de un arquitecto que estaba operando una transición al Renacimiento desde la propia tradición en la que se formó, sin duda arropado, o sencillamente impulsado, por un ambiente humanista que Vicente Lleó acertara a evocar en Nueva Roma, obra precursora de tantos enfoques posteriores ${ }^{42}$.

En este sentido, conviene tener en cuenta la naturaleza coral de una obra en la que resultaría crucial la intervención de algunos capitulares influyentes, entre los que destacan algunos nombres ya señalados por la historiografía, como Pedro Pinelo o Baltasar del Río ${ }^{43}$. En particular, este último merece una atención mayor

${ }^{40}$ El manejo simultáneo de repertorios góticos y renacentistas es también un hecho acreditado en las obras del Ayuntamiento, bajo la dirección del propio Riaño. En 1534, cuando se trabajaba en el Apeadero, el maestro cántabro había acogido a varios aprendices. Entre ellos, García de Buelna, Fernando Vargas y Martín de Oñate tallaron piezas para las bóvedas góticas de este espacio y, a la vez, para las ventanas y cornisas renacentistas de la fachada. MORALES, Alfredo J.: "El Ayuntamiento de Sevilla: maestros canteros, entalladores e imagineros", Laboratorio de Arte, 4, 1991, pp. 61-82.

${ }^{41}$ MORALES, Alfredo J.: "La arquitectura de la catedral...", op. cit., pp. 179-190.

${ }^{42}$ LLEÓ CAÑAL, Vicente: Nueva Roma: mitología y humanismo en el Renacimiento sevillano. Sevilla, 1979.

${ }^{43}$ MORALES, Alfredo J.: La Sacristía..., op. cit., pp. 59-60; y RECIO MIR, Álvaro: Sacrum Senatum, op. cit., pp. 82-87. 
que la recibida hasta el momento ${ }^{44}$. La decidida voluntad de ejecutar un proyecto a la antigua debió emanar de estas destacadas figuras, quienes pudieron proporcionar referencias tipológicas y formales esenciales, a través de dibujos y otros recursos, con el objeto de condicionar la orientación seguida por el maestro mayor. Por otra parte, tampoco podemos descartar la posible exposición del maestro cántabro a la deslumbrante figura de Siloe y otros maestros de la época. La falta de documentación al respecto no debe hacernos ignorar tal posibilidad cuando al menos algunos indicios podrían apuntar, si bien vagamente, la posibilidad de un trasvase de experiencias entre Granada y Sevilla. La presencia en Sevilla de entalladores altamente cualificados, algunos procedentes de Granada, pudo contribuir a la formalización de determinadas soluciones, un hecho ya apuntado tanto por Manuel Gómez-Moreno como por Javier Gómez Martínez ${ }^{45}$.

Tras la muerte de Riaño, la documentación de la obra refleja un parón temporal en los trabajos a la espera de una decisión sobre el curso del proyecto vigente y, desde el principio, un evidente protagonismo de Martín de Gaínza. Tras las consultas dirigidas a varios maestros de prestigio, entre las que destaca la significativa visita de Diego Siloe en abril de 1535, se encargó a Martín de Gaínza la dirección de los trabajos en un auto en el que aparece igualmente mencionado Siloe, presente todavía en ese momento en Sevilla ${ }^{46}$. En 1535, se trabajaba en la capilla mayor de la nueva sacristía, como evidencia la fecha recogida en una segunda cartela, y en 1537 se alcanzaba la cornisa del muro exterior, se había abovedado el conjunto de las tres cámaras de la Capilla Mayor y cerrado la bóveda de la Sacristía de los Cálices. Resueltos estos espacios, se estaba en disposición de atacar la gran cúpula, culminada finalmente en $1543^{47}$. Cuatro años después, con el solado de la gran sala, se daba la obra por concluida.

Fecha de recepción: 30 de octubre de 2018

Fecha de aceptación: 5 de febrero de 2019

${ }^{44}$ En relación con este personaje, el reciente estudio de Teodoro Falcón ha contribuido a saldar una deuda aún pendiente. FALCÓN MÁRQUEZ, Teodoro: "Baltasar del Río, Obispo de Scala, y su capilla en la Catedral de Sevilla", en Patronos y modelos en las relaciones entre Andalucía, Roma y el Sur de Italia. Málaga, 2012, pp. 59-88.

${ }^{45}$ GÓMEZ MORENO, Manuel: Las águilas..., op. cit., p. 87; y GÓMEZ MARTÍNEZ, Javier: El Gótico español de la Edad Moderna. Bóvedas de crucería. Valladolid, 1998, pp. 111-122.

${ }^{46}$ MORALES, Alfredo J.: La Sacristía..., op. cit., pp. 33-34.

${ }^{47}$ Ibidem, pp. 40-47. 

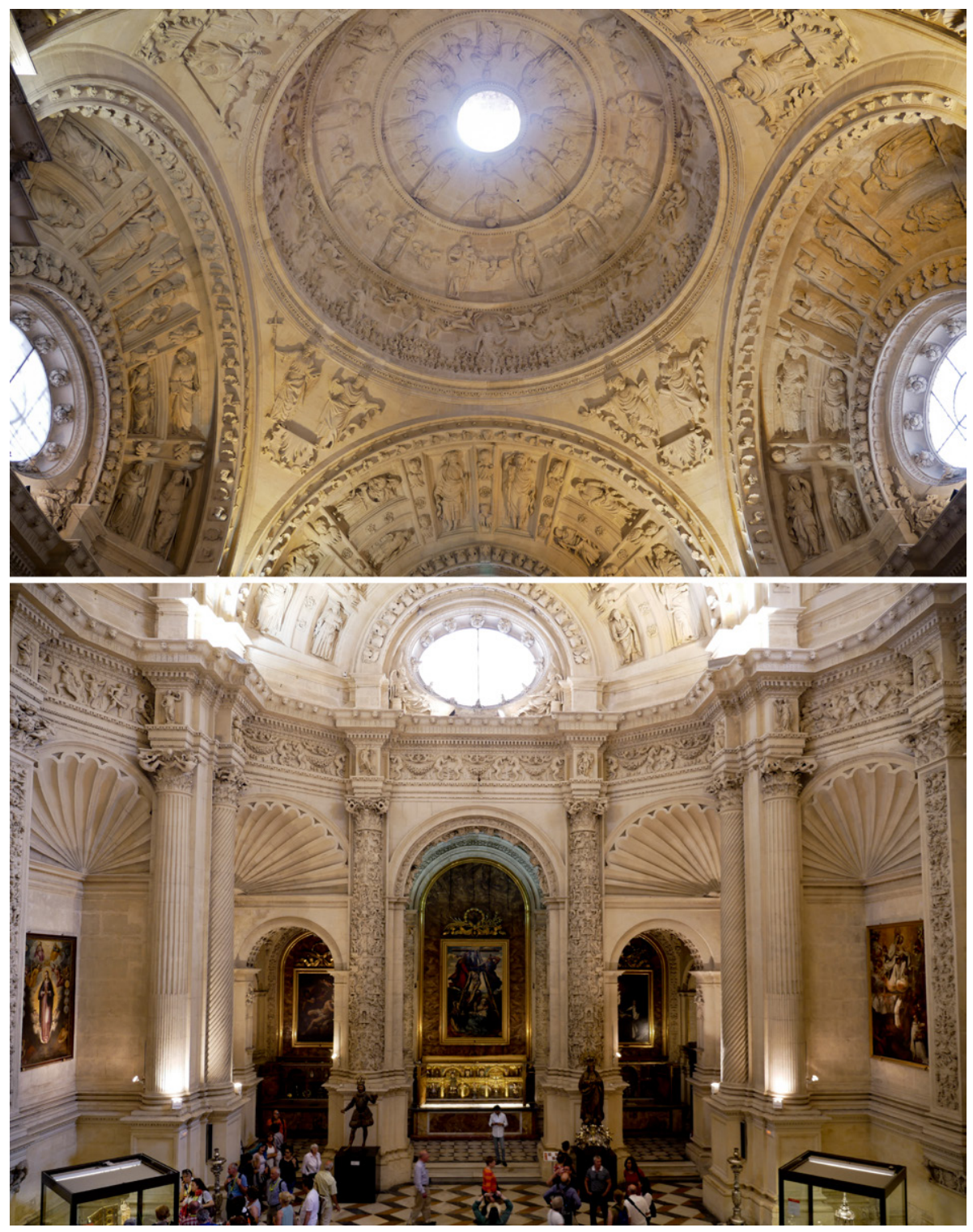

Figura 1. Sacristía Mayor de la catedral de Sevilla. 


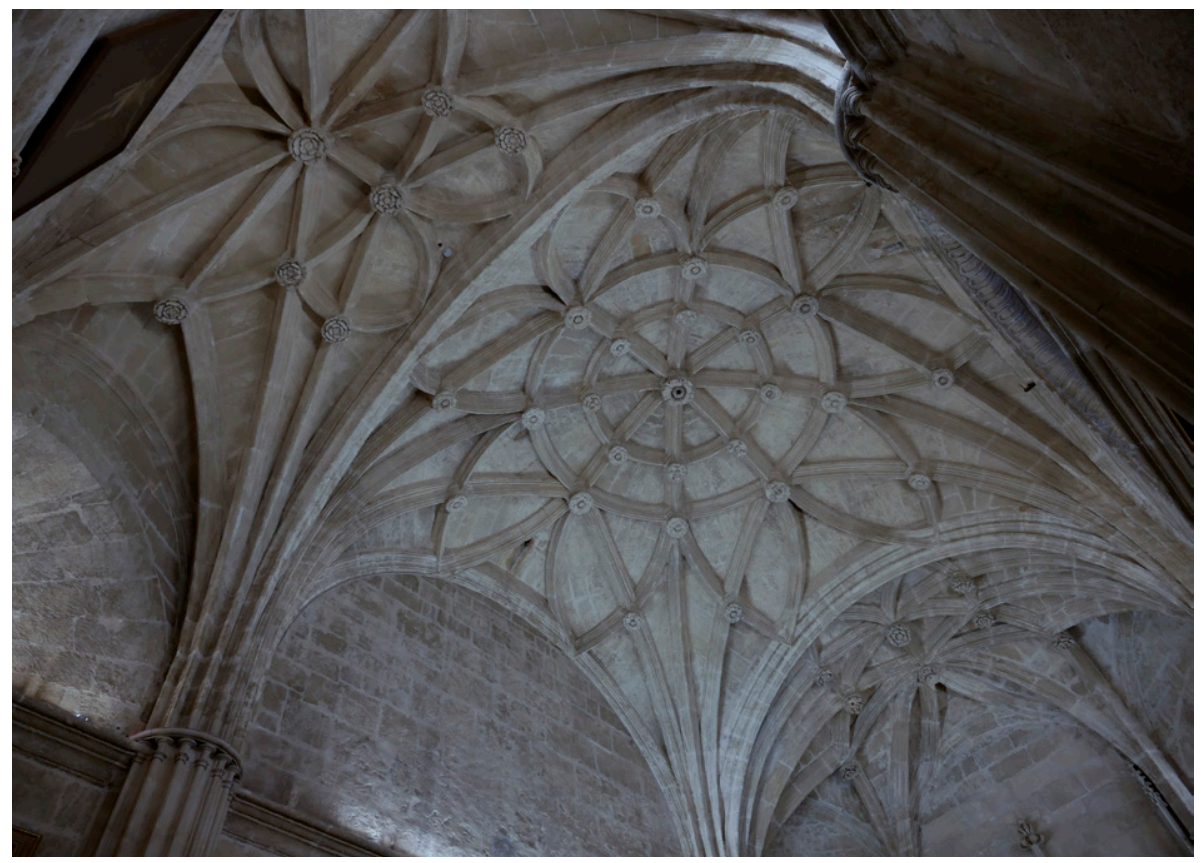

Figura 2. Sacristía de los Cálices de la catedral de Sevilla.

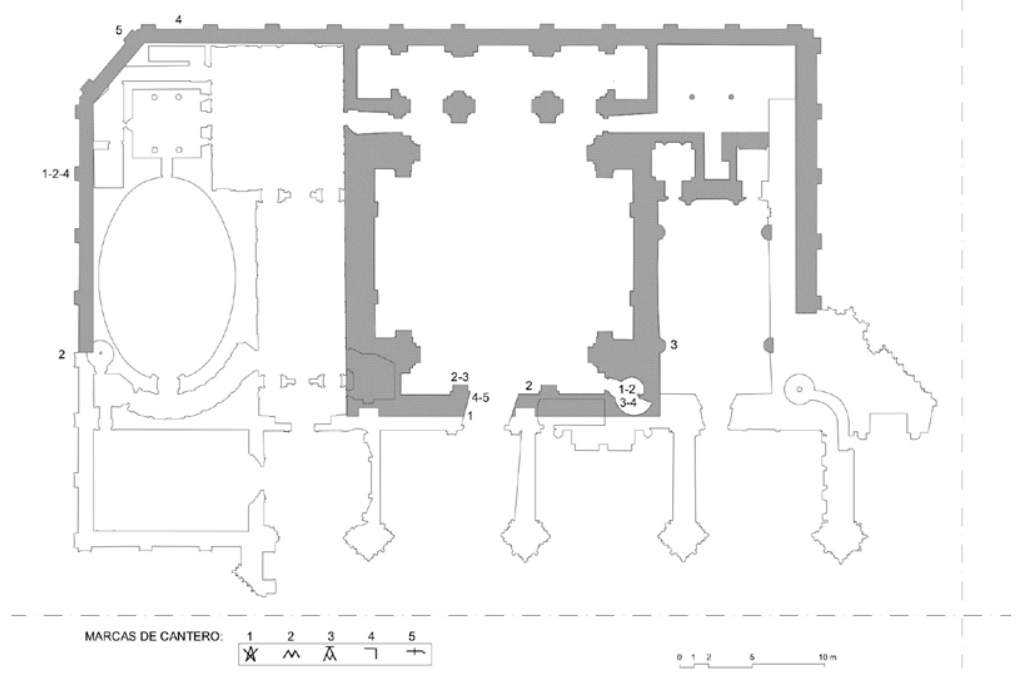

Figura 3. Conjunto de las sacristías: delimitación de la superficie de muros en obra a partir de 1532, con la posición de algunas marcas de cantero por debajo de los $4 \mathrm{~m}$ de altura. 


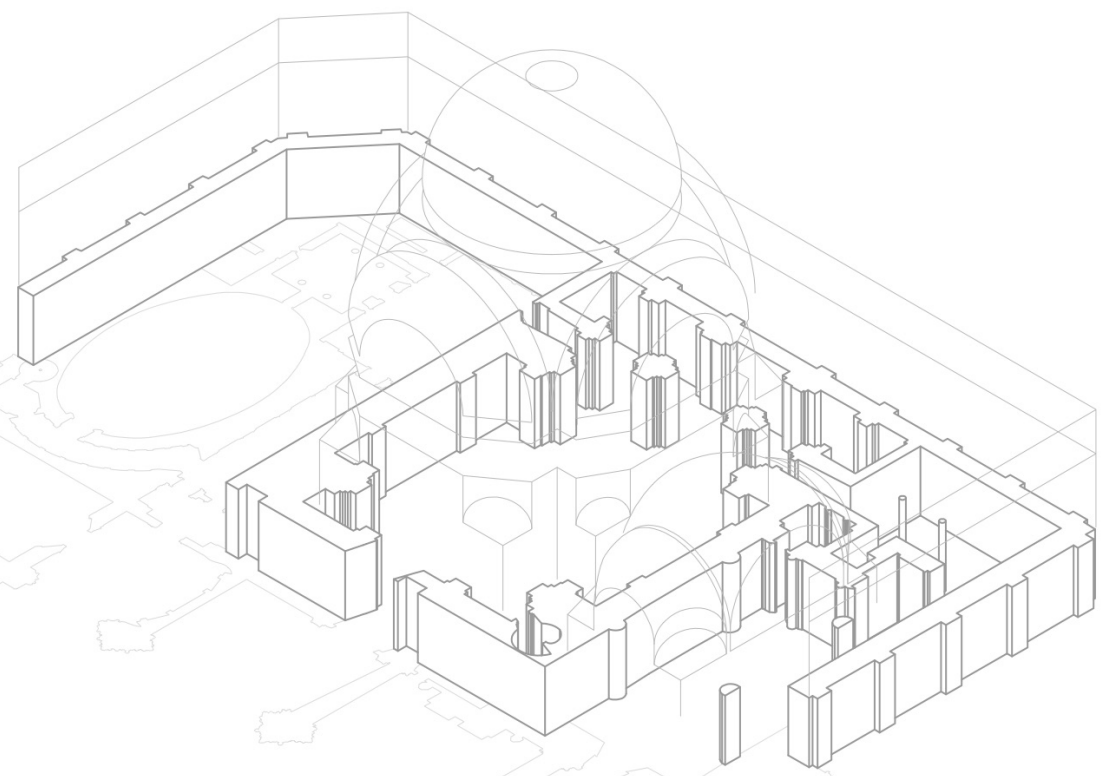

Figura 4. Conjunto de las sacristías: estimación de la altura media de los muros en función del volumen de piedra puesto a pie de obra entre 1532 y 1534. 